\title{
The Analysis of Selected Posturogram Parameters in Children with Scoliotic Changes
}

\author{
Jacek Wilczyński ${ }^{1}$, Natalia Habik², Katarzyna Bieniek², Sylwia Janecka², Przemysław Karolak ${ }^{2} \&$ Igor $^{2}$ \\ Wilczyński ${ }^{4}$ \\ ${ }^{1}$ Head of Posturology Department, Hearing and Balance Rehabilitation, Faculty of Medicine and Health sSciences, \\ Jan Kochanowski University in Kielce, Poland \\ ${ }^{2}$ Faculty of Medicine and Health Sciences, Jan Kochanowski University in Kielce, Poland \\ ${ }^{3}$ Faculty of Rehabilitation, University School of Physical Education in Krakow, Kraków, Poland \\ ${ }^{4}$ Outpatient Rehabilitation Centre for Children, State Health Care Center in Starachowice, Poland \\ Correspondence: Jacek Wilczyński, Head of Posturology Department, Hearing and Balance Rehabilitation, \\ Faculty of Medicine and Health Sciences, Jan Kochanowski University, Kielce, Al. IX Wieków Kielc 19, 25-317 \\ Kielce, Poland. Tel: 48-603-703-926. E-mail: jwilczyński@onet.pl
}

Received: May 22, 2018

Accepted: May 30, 2018

Online Published: July 15, 2018

doi:10.5539/mas.v12n8p38

URL: https://doi.org/10.5539/mas.v12n8p38

\begin{abstract}
The aim of the research was to analyze selected posturogram parameters in children with scoliotic changes. 28 girls aged 7-18 years old were involved in the study. Children attended to the Interschool Centre of Corrective Exercises in Starachowice. The research was conducted in June 2011. Spine research was made by Exhibeon digital radiography. Based on the size of the angle of spinal curvature there were identified scoliotic posture: $1-9^{\circ}$ and scoliosis: $\geq 10^{\circ}$. There were $21(75 \%)$ children with scoliotic posture, and $7(25 \%)$ with idiopathic scoliosis. The frequency and type of defect didn't depended on age. Postural reactions were examined by static-dynamic Tecnobody's ST 310 Plus Stability System platform. Perimeter was from 539,46 with opened eyes (OE) to 759,04 with closed eyes (CE). The difference in Romberg's Test was 219,58. Ellipse area was from 447,46 with opened eyes (OE) to 850,32 with closed eyes (CE). The difference in Romberg's Test was 402,86. Perimeter ratio was 146,68 , and Area ratio was 213,89 . Analysis of variance showed a significant effect of study options which clearly differentiates Permeter $(\mathrm{p}=0,000008)$ and Ellipse Area $(\mathrm{p}=0,029882)$ in the research with opened and closed eyes. In a study with closed eyes it has been observed a significant increase of posturogram variables. Analysis of variance for Area ratio didn't show any significant effects $(\mathrm{p}=0,376899)$ similarly for Perimeter ratio $(\mathrm{p}=0,523086)$. Posturogram variables generally decreased with age, however the analysis of variance didn't show any statistically significant effects. The analysis of the Spearman rank correlation of posturogram variables with age of examined persons also didn't show any significant associations.
\end{abstract}

Keywords: posturogram parameters, scoliotic changes, Tecnobody's Stability System platform

\section{Introduction}

The record which shows the way of the centre of feet pressure (COP) in a two-dimensional supporting plane is called posturogram or statokinesiogram. Most often assessed sway parameters are those, which are easiest to measure (Błaszczyk, 2016). The directions in this plane are determined by the letters $\mathrm{x}$ and $\mathrm{y}$, wherein $\mathrm{x}$ (or AP) means sways in the sagittal plane, and y (or ML) lateral deflections in the frontal plane (Aroeira et al., 2016). The most frequently analyzed and probably the most valuable parameter of posturogram is the path length of posturogram. The road traveled by the center of gravity during the test, depends on the imposed time of registration and the speed movement of the COG (or COP) during the study (Michoński et al., 2016). Usually impaired balance control of standing posture is manifested by prolongation of this road (Nishida et al., 2016). Because the chaotic movements of the center of gravity are two-dimensional, additional informations about postural stability can be obtained, by analyzing the individual components of the way of statokinesiogram, separately sways in the sagittal plane, and separately in the frontal plane (Wilczyński \& Ślężyński, 2016). Separate analysis of each component of posturogram allows to find, in which plane the instability intensifies. More information about the balance control provides the analysis of the entire envelope of posturogram, not just selected directions (Huec et al., 2016). If we 
will connect the extreme points of statokinesiogram with the lines, we will get an irregularly shaped polygon. The area of a figure calculated by the computer, depends on the range of sways in all directions and it is the another characteristic parameter of posturogram (Park et al., 2016). More often, somewhat to simplify the problem of analysis, researchers fits the sway points into a circle or ellipse (Bogie et al., 2014). The geometrical dimensions of these figures, for example the radius of a described circle or length rays and tilt axis of the ellipse, are another important indicators of the quality of balance control (Tam et al., 2014; Pialasse et al., 2016). The posture of a man standing in a standard two-legged support is characterized by a greater sways in the sagittal plane (Pialasse \& Simoneau, 2015; Yen et al., 2016). Movements of COG in the frontal plane are much smaller, and the increase of instability in this plane is usually effectively compensated by wider spaced feet (Khanal et al. 2016; Pialasse \& Simoneau, 2014). The range of observed sways in the sagittal plane is usually two or three times greater than in frontal plane, and that's why the ellipse more accurately covers the measurement points of statokinesiogram (Park et al. 2013; Paolucci et al., 2013; de Santiago et al., 2013; Talić et al., 2016). In addition to the surface of the ellipse, an important indicator of the quality of balance control is the slope of a longer axis of the ellipse (corresponding to the sways in the sagittal plane) relative to coordinate system (Berdishevsky et al., 2016; Gomez, Hresko \& Glotzbecker, 2016). Balance disorder, caused by scoliotic changes, in addition to the range increase of uncontrolled movements of the center of gravity of the body also causes characteristic changes seen in posturogram, for example the slope of axis of the ellipse (Yang et al., 2016; Seifert, Thielemann \& Bernstein, 2016). The aim of the research was to analyze selected posturogram parameters in children with scoliotic changes on Tecnobody's ST 310 Plus Stability System platform.

\section{Method}

\subsection{Participant (Subject) Characteristics}

The study included 28 girls aged 7-18 years old with scoliotic posture and idiopathic scoliosis. All respondents were selected intentionally. All research procedures were carried out in accordance with the 1964 Declaration of Helsinki and with the consent of the University Bioethic Board for Scientific Research affairs at Jan Kochanowski University in Kielce (Poland). Children attended to the Interschool Centre of Corrective Exercises in Starachowice (Poland). The research was conducted in June 2011.

\subsection{Research design}

Spine research was made by Exhibeon digital radiography. Pixel Technology's Exhibeon digital radiology is a valuable diagnostic tool, which replace a traditional X-ray film. Exhibeon runs on Linux and Microsoft Windows operating systems. With a browser, we can describe changes in bone structure, and soft tissues. Exhibeon currently supports 84 graphic image formats, compatible with DICOM, including animation formats presented in CINE mode. Exhibeon is able to cooperate simultaneously with multiple image archives - PACS servers. The program supports the format DICOMDIR, and allows to search the images inside catalog. It allows printing on DICOM printers, and their configuration, through the base device, is simple. Exhibeon digital radiology allows, among others, to outline the central sacral vertical line, visible on X-ray of the spine on the computer screen, measure of the angle of axial circle rotation and to determine the Cobb angle. Radiographs have been taken of a free-standing position, anterior-posterior projection and lateral. With a browser, we could describe changes in bone structure, and soft tissues. X-ray included lumbar, thoracic and cervical spine, chest, and pelvis with hip joints. The Cobb angle has been marked on X-ray of the spine, which is visible on the computer screen. For the study of posturogram, the computerized posturography has been used. Posturogram variables were examined by staticdynamic Tecnobody's ST 310 Plus Stability System platform.

\subsection{Measures and Covariates}

The research based on continuous observation of the centre of feet pressure (COP). By recording the horizontal deflection of the body (postural sway) as a function of time, the detailed information concerning the postural system has been obtained. The COP displacements reflected the movements of center of body mass (COM) in the frontal and sagittal plane. The frequency of signal was $20 \mathrm{~Hz}$. Change of the maximum pressure on the soles of the feet during the deviations of the body was perceived by mechanical-electronic transducer consisting of three sensors installed inside the platform. Recorded signal was processed from the analog information into digital, and then elaborated by computer program. The appropriate software created the possibility to calculate the resultant ground reaction force, which is the sum of the moments of the forces acting on the platform in three points of measurement. Vector addition of force moments allowed to designate the resultant ground reaction force at the moment, which is graphically presented as a dot on statokinesiogram. There was performed a standard stability rating test in a free-standing position (Romberg's Test). The test consisted of two successive samples lasting 30 seconds each: first with opened eyes ( $\mathrm{OE}$ - open eys), second with closed eyes (CE-close eys). Measurements 
were taken in the morning. The tested person was carefully instructed about the test sequence. The silence has been assured during examination, because auditory stimuli acting on man in terms of attention can significantly impair the postural reflexes. The examined person has been ensured about the total harmlessness of the performed test. During the study, the investigator was behind the tested person all the time, not passing any messages. During the measurements with opened eyes (OE), the examined person has been asked to focus his sight on a point of reference located on the computer screen. The center of vision speckle was located at a distance of 1 meter from examined person. Before starting the test with closed eyes (CE), researcher made sure that the tested person is able to maintain an upright posture without visual control. The examined person stood on a platform barefoot, because shoes could interfere his posture. The feet were set with careful precision: heels $2 \mathrm{~cm}$ from each other, feet apart at the angle of $30^{\circ}$, so that the center of gravity of a polygon base was in the sagittal axis of the platform at a distance of $3 \mathrm{~cm}$ from its center. To facilitate the correct positioning of the tested person, the platform was equipped with a pattern to keep the feet apart. The examined person took a habitual position with arms lowered along the torso and head straight. Test started at the time when investigated person took a posture, and on the screen the way of centre of feet pressure deviation was displayed. It has been analyzed the selected posturogram parameters, which records the centre of feet pressure deviations (COP):

- Perimeter. It is the total length of the path traveled by the COP in both planes during the oscillation (mm).

- Ellipse area. It is the total area which circled the COP in both planes during the oscillation $\left(\mathrm{mm}^{2}\right)$.

- Perimeter ratio. It is the ratio of circumference (perimeter) with eyes closed (CE) to the circumference with eyes opened (OE) in Romberg's Test.

- Area ratio. It is the ratio of ellipse area with eyes closed (CE) to the area with eyes opened (OE) in Romberg's Test.

Depending on the compatibility of variable distributions with normal distribution, and the value of skewness and kurtosis, parametric or non-parametric tests have been used. Variables were verified in terms of normal distribution by Shapiro-Wilk test. Variability of quantitative traits in terms of categorial features (age group, study options) were verified by analysis of variance with single and double classification. The level of significance was $p<0,05$.

\section{Results and Discussion}

Based on the size of the angle of spinal curvature there were identified scoliotic posture $\left(1-9^{\circ}\right)$ and scoliosis $\left(\geq 10^{\circ}\right)$. There were 21 (75\%) children with scoliotic posture, and with idiopathic scoliosis 7 (25\%). The frequency and type of defect didn't depended on age. Perimeter was from 539,46 with opened eyes (OE) to 759,04 with eyes closed (CE). The difference in Romberg's Test was 219,58. Ellipse area was from 447,46 with opened eyes (OE) to 850,32 with closed eyes (CE). The difference in Romberg's Test was 402,86. Perimeter ratio was 146,68 and Area ratio was 213,89 (Tab. 1).

Table 1. Posturogram parameters with eyes opened (OE) and closed (CE)

\begin{tabular}{lcrrrrrrrr}
\hline Postural reactions & $\mathrm{n}$ & Average & \multicolumn{1}{c}{ Med } & \multicolumn{1}{c}{ Min } & Max & Range & Standard deviation & Skewn & Kurtos \\
\hline Perimeter (OE) & 28 & 539,46 & 493 & 248 & 1079 & 831 & 195,80 & 1,272 & 1,825 \\
Ellipse Area (OE) & 28 & 447,46 & 438,5 & 102 & 1660 & 1558 & 314,37 & 2,260 & $\mathbf{7 , 6 1 6}$ \\
Perimeter (CE) & 28 & 759,04 & 723 & 449 & 1330 & 881 & 232,50 & 0,714 & $-0,106$ \\
Ellipse Area (CE) & 28 & 850,32 & 647 & 144 & 3776 & 3632 & 781,18 & 2,525 & $\mathbf{7 , 1 6 5}$ \\
Perimeter ratio & 28 & 146,68 & 140,5 & 71 & 226 & 155 & 36,45 & 0,271 & $-0,338$ \\
Area ratio & 28 & 213,89 & 187,5 & 31 & 719 & 688 & 149,03 & 1,691 & 3,896 \\
\hline
\end{tabular}

Perimeter in the age group of 7-11 was from 659,00 with opened eyes (OE) to 830,00 with closed eyes (CE). The difference in Romberg's Test was 171. In the age group of 12-14 was from 483,53 with opened eyes (OE) to 756,61 with closed eyes (CE). The difference in Romberg's Test was 273,08. In the age group of 15-18 was from 506,71 with opened eyes (OE) to 682,42 with closed eyes (CE). The difference in Romberg's Test was 175,71 (Tab. 2).

Table 2. Perimeter and Ellipse Area in age groups

\begin{tabular}{|c|c|c|c|c|c|c|}
\hline \multirow{2}{*}{ Independent variables } & \multirow{2}{*}{ (OE-CE) } & \multicolumn{4}{|c|}{ Dependent variable } & \\
\hline & & Average & Standard error & $-95,00 \%$ & $95,00 \%$ & 11 \\
\hline
\end{tabular}




\begin{tabular}{|c|c|c|c|c|c|c|}
\hline 7-11 years old (1) & Perimeter (OE) & 659,00 & 66,05 & 522,96 & 795,04 & 8 \\
\hline 7-11 years old (2) & Perimeter (CE) & 830,00 & 83,00 & 659,04 & 1000,95 & 8 \\
\hline $12-14$ years old (3) & Perimeter (OE) & 483,53 & 51,81 & 376,82 & 590,25 & 13 \\
\hline $12-14$ years old (4) & Perimeter (CE) & 756,61 & 65,11 & 622,50 & 890,72 & 13 \\
\hline $15-18$ y & rimeter $(\mathrm{OE})$ & 506,71 & 70,61 & 361,28 & 652,14 & 7 \\
\hline $15-18$ years old $(6)$ & Perimeter (CE) & 682,42 & 88,73 & 499,67 & 865,18 & 7 \\
\hline \multirow{2}{*}{ Independent variables } & \multirow{2}{*}{ (OE-CE) } & \multicolumn{4}{|c|}{ Dependent variable } & \\
\hline & & Average & Standard & -9 & $95,00 \%$ & \\
\hline $7-11$ ye & Ellipse Are & 681,87 & 101,24 & 473,36 & 890,38 & 8 \\
\hline $7-11$ years old (2) & Ellipse Area (CE) & 892,87 & 281,12 & 313,89 & 1471,85 & 8 \\
\hline 12-14 years old (3) & Ellipse Area (OE) & 362,84 & 79,41 & 199,27 & 526,41 & 13 \\
\hline $12-14$ years old (4) & Ellipse Area (CE) & 965,61 & 220,53 & 511,42 & 1419,80 & 13 \\
\hline $15-18$ years old (5) & Ellipse Area (OE) & 336,71 & 108,23 & 113,81 & 559,61 & 7 \\
\hline $15-18$ years old (6) & Ellipse Area (CE) & 587,57 & 300,53 & $-31,38$ & 1206,52 & 7 \\
\hline
\end{tabular}

Ellipse area in the age group of 7-11 was 681,87 with opened eyes (OE) to 892,87 with closed eyes (CE). The difference in Romberg's Test was 211. In the age group of 12-14 was from 362,84 with opened eyes (OE) to 965,61 with closed eyes (CE). The difference in Romberg's Test was 602,77. In the age group of 15-18 was from 336,71 with opened eyes (OE) to 587,57 with closed eyes (CE). The difference in Romberg's Test was 250,86 (Tab. 3).

Table 3. Perimeter Ratio and Area Ratio in age groups

\begin{tabular}{llllllll}
\hline \multirow{2}{*}{ Independent variables } & Perimeter Ratio & Confidence & Confidence & \multicolumn{2}{l}{ Perimeter Ratio } \\
& Average & $-95,00 \%$ & $95,00 \%$ & $\mathrm{n}$ & Standard deviation & Min. & Max. \\
\hline 7-11 years old (1) & 134,87 & 105,36 & 164,38 & 8 & 35,30 & 71 & 181 \\
$12-14$ years old (2) & 156,92 & 133,43 & 180,41 & 13 & 38,87 & 108 & 226 \\
$15-18$ years old (3) & 141,14 & 111,13 & 171,15 & 7 & 32,44 & 102 & 183 \\
Total & 146,68 & 132,54 & 160,81 & 28 & 36,44 & 71 & 226 \\
\hline \multirow{2}{*}{ Independent variables } & Area ratio & Confidence & Confidence & Area ratio & & & \\
& Average & $-95,00 \%$ & $95,00 \%$ & n & s & Min. & Max. \\
\hline 7-11 years old (1) & 174,87 & 83,64 & 266,10 & 8 & 109,12 & 31 & 337 \\
$12-14$ years old (2) & 248,38 & 133,10 & 363,66 & 13 & 190,76 & 63 & 719 \\
$15-18$ years old (3) & 194,42 & 110,55 & 278,30 & 7 & 90,69 & 92 & 326 \\
Total & 213,89 & 156,10 & 271,68 & 28 & 149,03 & 31 & 719 \\
\hline
\end{tabular}

Total Perimeter ratio was 146,68 . In the age group of $7-11$ was 134,87 , in the age group of $12-14$ was 156,92 , and in the age group of 15-18 was 141,14 . Total Area ratio was 213,89 . In the age group of 7-11 it was 174,87 . In the age group of 12-14 it was 248,38 , and in the age group of $15-18$ was 194,42 . The analysis of variance with the single classification showed a significant effect of study options in Romberg's Test (OE/CE) both for Perimeter $(\mathrm{p}=0,000008)$ as well as Ellipse area $(\mathrm{p}=0,029882)$ (Tab. 4). Posturogram variables generally decreased with age, but this decrease wasn't statistically significant (Tab. 4). The analysis of variance with the single classification for Perimeter ratio and Area ratio showed no significant effects (Tab. 4). Also the correlation analysis of posturogram variables with opened and closed eyes and age showed no significant associations (Tab. 4).

Table 4. The analysis of variance for repeated measures (Note 1)

\begin{tabular}{llllll}
\hline Perimeter & & & & & \\
\hline Independent variables & SS & DF & MS & F & $p$ \\
\hline
\end{tabular}




\begin{tabular}{|c|c|c|c|c|c|}
\hline Free term & 22264980 & 1 & 22264980 & 308,81 & 0 \\
\hline Age groups & 209145 & 2 & 104573 & 1,45 & 0,25 \\
\hline Error & 1802446 & 25 & 72098 & & \\
\hline OE-CE & 557081 & 1 & 557081 & 31,0743 & 0,000008 \\
\hline OE-CE - Age groups & 34777 & 2 & 17389 & 0,96 & 0,39 \\
\hline Error & 448185 & 25 & 17927 & & \\
\hline \multicolumn{6}{|l|}{ Ellipse Area } \\
\hline Independent variables & SS & $\begin{array}{l}\text { DF } \\
\text { DF }\end{array}$ & MS & $\mathrm{F}$ & $\mathrm{p}$ \\
\hline Free term & 21245034 & 1 & 21245034 & 52,54 & 0 \\
\hline Age groups & 801211 & 2 & 400606 & 0,99 & 0,38 \\
\hline Error & 10107697 & 25 & 404308 & & \\
\hline OE-CE & 1643698 & 1 & 1643698 & 5,30357 & 0,029882 \\
\hline OE-CE - Age groups & 487872 & 2 & 243936 & 0,78 & 0,46 \\
\hline Error & 7748081 & 25 & 309923 & & \\
\hline \multicolumn{6}{|l|}{ Perimeter Ratio } \\
\hline SS & $\mathrm{df}$ & MS & SS & $\mathrm{df}$ & \\
\hline Effect & Effect & Effect & Error & Error & Error \\
\hline 2693,45 & 2 & 1346,73 & 33174,7 & 25 & 1326,99 \\
\hline \multicolumn{6}{|l|}{ Area ratio } \\
\hline SS & $\mathrm{df}$ & MS & SS & & $\mathrm{df}$ \\
\hline Effect & Effect & Effect & Error & Error & Error \\
\hline 30297,01 & 2 & 15148,51 & 569407,7 & 25 & 22776,31 \\
\hline \multicolumn{6}{|c|}{ The analysis of correlation of posturogram variables with opened and closed eyes and age } \\
\hline \multicolumn{2}{|l|}{ Posturogram variables } & \multicolumn{2}{|c|}{ Age $(\mathrm{OE})$} & \multicolumn{2}{|l|}{ Age $(\mathrm{CE}$} \\
\hline \multicolumn{2}{|l|}{ Perimeter } & \multicolumn{2}{|c|}{$\mathrm{R}=-0,29 ; \mathrm{p}=0,13$} & \multicolumn{2}{|c|}{$R=-0,31 ; p=0,10$} \\
\hline \multicolumn{2}{|l|}{ Ellipse Area } & \multicolumn{2}{|c|}{$\mathrm{R}=-0,32 ; \mathrm{p}=0,087$} & \multirow{2}{*}{\multicolumn{2}{|c|}{$R=-0,25 ; p=0,18$}} \\
\hline \multirow{2}{*}{\multicolumn{2}{|c|}{$\begin{array}{l}\text { Perimeter Ratio } \\
\text { Area ratio }\end{array}$}} & \multirow{2}{*}{\multicolumn{2}{|c|}{$\begin{array}{l}\mathrm{R}=-0,04 ; \mathrm{p}=0,81 \\
\mathrm{R}=-010 \cdot \mathrm{n}=05 \mathrm{~s}\end{array}$}} & & \\
\hline & & & & & \\
\hline
\end{tabular}

Within the meaning of etiopathogenesis, scoliosis is only a symptom, an external expression of unrecognized pathology, which can occur in any segment of the spine and in children of different ages. In the present state of knowledge it is reasonable to talk more about the etiological factors, not about the theory (genetical, metabolic etc.) of scoliosis formation. Currently the concept which has got the most supporters is a multifactorial, including genetical (CHD7 gene) conditioned pathology of central nervous system, which causes changes in postural system (Tam et al. 2014). Scoliotic posture means a tendency to deflect the axis of the spine from a straight line, associated rather with the wrong habit of keeping the individual body segments. At the beginning each spontaneously growing scoliosis is a gradual low curvature - scoliotic posture (Myers, 2016). After time it reveals the actual development trends (Byun \& Han, 2016; Kim \& Hwang, 2016). In a pathobiomechanical term, scoliosis is compensated when the original deflection (a) goes smoothly into compensatory, proximal and distal deflection (Porte et al. 2016). Then the compensatory deflections are enough developed, and they equilibrate the original deflection. The sum of their angle values corresponds approximately to the angle value of original deflection. Scoliosis is the result of original imbalance of vertically poised spine. Posturogram variables are the elements of body balance (van Herwijnen et al. 2016). Overall assessment of efficiency of the balance system provides the posturography test. This is possible because of the reactions analysis and postural strategies, which forms the basis of mechanisms that promote the body in balance (Saifi, Kang \& Lehman, 2016). Balance is a certain state of postural system, which is characterized by the vertical orientation of the body achieved due to aligning the forces acting on a body and their moments (Nikolova et al. 2015). The balance is provided by the nervous system through the reflex tension of respective muscle groups called anti-gravity muscles (Romano et al. 2008). Some informations about the body balance gives the analysis of individual posturogram variables. Scoliosis is a disease associated with disorders of the central stabilization of the body caused by postural hypotonia. Disorders of posturogram variables that occurs in scoliosis affects on pathoetiology of scoliosis and reversal movements of individual body segments increase the amplitudes of these variables. Stabilization disorders associated with dysfunction of CNS, and postural hypotonia seen in the increased posturogram variables, are probably primary and they precede scoliotic changes (Wilczyński et al., 2018). 


\section{Conclusions}

The analysis of variance showed a significant effect of study options which clearly differentiates Perimeter and Ellipse Area in Romberg's Test. In a study with eyes closed a significant increase of these variables has been observed. Posturogram variables generally decreased with age, however, analysis of variance showed no statistically significant effects. The analysis of the Spearman rank correlation of posturogram variables with age of examined persons also showed no significant associations.

\section{References}

Aroeira, R. M., de Las Casas, E. B., Pertence, A. E., Greco, M., \& Tavares, J. M. (2016). Non-invasive methods of computer vision in the posture evaluation of adolescent idiopathic scoliosis. J Bodyw Mov Ther, 20(4), 832-843. https://doi.org/10.1016/j.jbmt.2016. 02.004

Berdishevsky, H., Lebel, V. A., Bettany-Saltikov, J., Rigo, M., Lebel, A., \& Hennes, A., et al. (2016). Physiotherapy scoliosis-specific exercises - a comprehensive review of seven major schools, Scoliosis Spinal Disord, 4(11). https://doi.org/10.1186/s13013-016-0076-9.

Błaszczyk, J. W. (2016). The use of force-plate posturography in the assessment of postural instability. Gait Posture, 44, 1-6.

Bogie, R., Roth, A. K., de Faber, S., de Jong, J. J., \& Welting, T. J., et al. (2014). Novel radiopaque ultrahigh molecular weight polyethylene sublaminar wires in a growth-guidance system for the treatment of early-onset scoliosis: feasibility in a large animal study. Spine, 39(25), 1503-1509.

Byun, S., \& Han, D. (2016). The effect of chiropractic techniques on the Cobb angle in idiopathic scoliosis arising in adolescence. $J$ Phys Ther Sci., 28(4), 1106-110.

de Santiago, H. A., Reis, J. G., Gomes, M. M., \& da Silva Herrero, C. F., et al. (2013). The influence of vision and support base on balance during quiet standing in patients with adolescent idiopathic scoliosis before and after posterior spinal fusion. Spine J., 13(11), 1470-1476. https://doi.org/10.1016/j.spinee.2013.03.027.

Gomez, J. A., Hresko, M. T., \& Glotzbecker, M. P. (2016). Nonsurgical Management of Adolescent Idiopathic Scoliosis. J Am Acad Orthop Surg, 24(8), 555-564.

Khanal, M., Arazpour, M., Bahramizadeh, M., Samadian, M., \& Hutchins, S. W., et al. (2016). The influence of thermoplastic thoraco lumbo sacral orthoses on standing balance in subjects with idiopathic scoliosis. Prosthet Orthot Int., 40(4), 460-466.

Kim, G., \& Hwang, P. N. (2016). Effects of Schroth and Pilates exercises on the Cobb angle and weight distribution of patients with scoliosis. J Phys Ther Sci, 28 (3), 1012-1015.

Le Huec, J. C., Cogniet, A., Mazas, S., \& Faundez. A. (2016). Lumbar scoliosis associated with spinal stenosis in idiopathic and degenerative cases. Eur J Orthop Surg Traumatol, 26(7), 705-712.

Michoński, J., Walesiak, K., Pakuła, A., Glinkowski, W., \& Sitnik, R. (2016). Monitoring of spine curvatures and posture during pregnancy using surface topography - case study and suggestion of method. Scoliosis Spinal Disord, 17(11), 31.

Myers, L. K. (2016). Application of neuroplasticity theory through the use of the Feldenkrais Method with a runner with scoliosis and hip and lumbar pain: A case report. J Bodyw Mov Ther., 20(2), 300-309.

Nikolova, S., Yablanski, V., Vlaev, E., Stokov, L., Savov, A., \& Kremensky, I. (2015). Association between Estrogen Receptor Alpha Gene Polymorphisms and Susceptibility to Idiopathic Scoliosis in Bulgarian Patients: A Case-Control Study. Open Access Maced J Med Sci., 3(2), 278-282.

Nishida, M., Nagura, T., Fujita, N., Hosogane, N., \& Tsuji, T., et al. (2016). Position of the major curve influences asymmetrical trunk kinematics during gait in adolescent idiopathic scoliosis. Gait Posture, 11(51), 142-148.

Paolucci, T., Morone, G., Di Cesare, A., Grasso, M. R., Fusco, A., \& Paolucci. S., et al. (2013). Effect of Chêneau brace on postural balance in adolescent idiopathic scoliosis: a pilot study. Eur J Phys Rehabil Med, 49(5), 649-657.

Park, H. J., Sim, T., Suh, S. W., Yang, J. H., Koo, H., \& Mun, J. H. (2016). Analysis of coordination between thoracic and pelvic kinematic movements during gait in adolescents with idiopathic scoliosis. Eur Spine J., 25(2), 385-393.

Park, J. Y., Par, G. D., Lee, S. G., \& Lee, J. C. (2013). The effect of scoliosis angle on center of gravity sway. J Phys Ther Sci., 25(12), 1629-1631. 
Pialasse, J. P., \& Simoneau, M. (2014). Effect of bracing or surgical treatments on balance control in idiopathic scoliosis: three case studies. J Can Chiropr Assoc, 58(2), 131-140.

Pialasse, J. P., Descarreaux, M., Mercier, P., \& Simoneau. M. (2015). Sensory reweighting is altered in adolescent patients with scoliosis: Evidence from a neuromechanical model. Gait Posture, 42(4), 558-563.

Pialasse, J. P., Mercier, P., Descarreaux, M., \& Simoneau, M. (2016). Sensorimotor Control Impairment in Young Adults with Idiopathic Scoliosis Compared With Healthy Controls. J Manipulative Physiol Ther, 39(7), 473479 .

Porte, M., Patte, K., Dupeyron, A. \& Cottalorda, J. (2016). Exercise therapy in the treatment of idiopathic adolescent scoliosis: Is it useful? Arch Pediatr, 23(6), 624-628.

Romano, M., Ziliani, V., Atanasio, S., Zaina, F., \& Negrini, S. (2008). Do imbalance situations stimulate a spinal straightening reflex in patient with adolescent idiopathic scoliosis? Stud Health Technol Inform, 140, 307309.

Saifi, C., Kang, D. G., \& Lehman, R. A. (2016). Decision making for upper instrumented vertebra in thoracolumbar/lumbar adolescent idiopathic scoliosis: can we stop below the end vertebra? Spine J., 16(3), 288-290.

Seifert, J., Thielemann, F., \& Bernstein, P. (2016). Adolescent idiopathic scoliosis: Guideline for practical application. Orthopade, 45(6), 509-517.

Talić, G., Ostojić, L., Bursać, S. N., Nožica-Radulović, T., \& Stevanović-Papić, D. (2016). Idiopathic Scoliosis from Psychopathological and Mind-Body Medicine Perspectives. Psychiatr Danub, 28(4), 357-362.

Tam, E. M., Yu, F. W., Hung, V. W., Liu, Z., Liu, K. L., Ng, B. K., et al. (2014). Are volumetric bone mineral density and bone micro-architecture associated with leptin and soluble leptin receptor levels in adolescent idiopathic scoliosis?-A case-control study. PLoS One, 6(2), e87939. https://doi.org/10.1371/journal.pone.0087939

van Herwijnen, B., Evans, N. R., Dare, C. J., \& Davies, E. M. (2016). An intraoperative irrigation regimen to reduce the surgical site infection rate following adolescent idiopathic scoliosis surgery. Ann R Coll Surg Engl, 98(5), 320-323.

Wilczyński, J., \& Ślężyński, J. (2016). Postural reactions of girls and boys aged 12-15 years evaluated using Romberg test. Medical Studies, 32(2), 109-115.

Wilczyński, J., Bieniek, K., Habik, N., Janecka, S., \& Karolak, P. (2018). Body posture and balance reactions in girls and boys aged 12-15 years. Modern Applied Science, 12(4), 89-97. https://doi.org/10.5539/mas.v12n4p89

Yang, X., Song, Y., Liu, L., Zhou, C., Zhou, Z., \& Wang, L. (2016). Emerging S-shaped curves in congenital scoliosis after hemivertebra resection and short segmental fusion. Spine J., 16(10), 1214-1220.

Yen, T. C., Toosizadeh, N., Howe, C., Dohm, M., Mohler, J., \& Najafi, B. (2016). Postural Balance Parameters as Objective Surgical Assessments in Low Back Disorders: A Systematic Review. J. Appl Biomech, 32(3), 316323.

\section{Note}

Note 1. In analysis of ariance the symbols mean: SS - sum of square, DF -degree of freedom, MS -mean of squares, $\mathrm{F}$ - ratio of MS effect to MS error, $\mathrm{p}$ - level of significance.

\section{Copyrights}

Copyright for this article is retained by the author(s), with first publication rights granted to the journal.

This is an open-access article distributed under the terms and conditions of the Creative Commons Attribution license (http://creativecommons.org/licenses/by/4.0/). 